\title{
Buccal infiltration injection without a $4 \%$ articaine palatal injection for maxillary impacted third molar surgery
}

\author{
Som Sochenda ${ }^{1}$, Chakorn Vorakulpipat ${ }^{1}$, Kumar $\mathrm{K} \mathrm{C}^{1}$, Chavengkiat Saengsirinavin ${ }^{1}$, \\ Manus Rojvanakarn", Natthamet Wongsirichat ${ }^{1,2}$ \\ ${ }^{l}$ Department of Oral \& Maxillofacial Surgery, Faculty of Dentistry, Mahidol University, ${ }^{2}$ Consultant of International \\ College of Dentistry Committee, Walailuk University International College of Dentistry, Bangkok, Thailand
}

\begin{abstract}
J Korean Assoc Oral Maxillofac Surg 2020;46:250-257)
Objectives: Palatal infiltration is the most painful and uncomfortable anesthesia technique for maxillary impacted third molar surgery (MITMS). This approach could cause patients distress and aversion to dental treatment. The aim of this study was to evaluate the anesthetic efficacy of a buccal infiltration injection without a palatal injection in MITMS.

Materials and Methods: This prospective research study was a crossover split mouth-randomized controlled trial. Twenty-eight healthy symmetrical bilateral MITMS patients (mean age, 23 years) were randomly assigned to two groups. Buccal infiltration injections without palatal injections were designated as the study group and the buccal with palatal infiltration cases were the control group, using 4\% articaine and 1:100,000 epinephrine. The operation started after 10 minutes of infiltration. Pain assessment was done using a visual analogue scale and a numeric rating scale after each injection and extraction procedure. Similarly, the success rate, hemodynamic parameters, and additional requested local anesthetic were assessed.

Results: The results showed that the pain associated with local anesthetic injections between both groups were significantly different. However, the success rates between the groups were not significantly different. Postoperative pain was not significant between both groups and a few patients requested an additional local anesthetic, but the results were not statistically significant. For hemodynamic parameters, there was a significant difference in systolic pressure during incision, bone removal, and tooth elevation. In comparison, during the incision stage there was a significant difference in diastolic pressure; however, other steps in the intervention were not significantly different between groups.

Conclusion: We concluded that buccal infiltration injection without palatal injection can be an alternative technique instead of the conventional injection for MITMS.
\end{abstract}

Key words: Anesthesia, Infiltration, Articaine, Maxilla, Third molar surgery

[paper submitted 2019. 4. 23 / revised 2019. 5. 29 / accepted 2019. 6. 3]

\section{Introduction}

Maxillary and mandibular third molars are the most commonly embedded teeth, followed by maxillary canines. The impacted teeth can be treated by eliminating the obstruction or interference or taking out the tooth itself ${ }^{1}$. Upper and lower embedded third molar surgery is usually done with local an-

\section{Chakorn Vorakulpipat}

Department of Oral \& Maxillofacial Surgery, Faculty of Dentistry, Mahidol University, 6 Yothi Street, Rachathewee District, Bangkok 10400, Thailand

TEL: +66-2200-7777 FAX: +66-2200-7777

E-mail: chakorn.vor@mahidol.ac.th

ORCID: https://orcid.org/0000-0001-6627-8732

(c) This is an open-access article distributed under the terms of the Creative Commons Attribution Non-Commercial License (http://creativecommons.org/ licenses/by-nc/4.0/), which permits unrestricted non-commercial use, distribution, and reproduction in any medium, provided the original work is properly cited.

Copyright (C) 2020 The Korean Association of Oral and Maxillofacial Surgeons. All rights reserved. esthesia or general anesthesia, according to the severity and anticipated difficulty, patient preference or in critical cases $^{2,3}$. In maxillary impacted third molar surgery (MITMS), the painless technique of applying a maxillary conventional local anesthetic injection consists of buccal vestibular and palatal infiltration injections. The palatal infiltration injection is consistently painful ${ }^{4-7}$ because of the tight attachment of the palatal mucosa towards the underlying periosteal bone and the nerve supply.

The previous research of Lima-Júnior et al. ${ }^{8}$ evaluated the buccal vestibular and palatal infiltration injection of $4 \%$ articaine with different vasoconstrictors without palatal injection and studied the efficacy of buccal infiltration injection distribution using $4 \%$ articaine for the maxillary third molar extraction. A previous study by Bataineh and Al-Sabri ${ }^{9}$ considered "pain control" using $4 \%$ articaine on buccal mucosa 
without requiring palatal administration for removing maxillary teeth, and they also compared the anesthetic effect and pain control in the maxillary anterior and posterior areas. A study by Uckan et al. ${ }^{10}$ showed that $4 \%$ articaine and 1:100,000 epinephrine could anesthetize the palatal area for maxillary tooth extraction, without requiring a palatal infiltration injection.

A randomized controlled trial conducted by Badcock et al. ${ }^{11}$ studied the removal of maxillary third molars with buccal infiltration injections of 2\% lignocaine and 1:80,000 epinephrine bilaterally and on the palatal side using $0.2 \mathrm{~mL}$ of lignocaine without vasoconstrictors versus normal saline. A previous study by Fan et al. ${ }^{12}$ compared the pain experienced during maxillary tooth removal using $4 \%$ articaine and 1:100,000 epinephrine versus without palatal injection, using a pain visual analogue scale (VAS) tool.

Therefore, we expected that buccal vestibular infiltration administration with 4\% articaine and 1:100,000 epinephrine without palatal infiltration injection would have similar ef- ficacy as anesthesia and a similar success rate compared to buccal infiltration injection with palatal infiltration injection (conventional technique) in MITMS patients. The aim of this current research was to assess the anesthetic efficacy of $4 \%$ articaine and 1:100,000 epinephrine with buccal vestibular infiltration injections without palatal infiltration injections compared with the buccal vestibular infiltration injections with palatal infiltration injections for MITMS.

\section{Materials and Methods}

This research was approved by the Committee in the Ethics of Research in Human Beings of Dentistry and Pharmacy at the Mahidol University Institutional Review Board with protocol No. COA MU-DT/PY-IRB 2018/039.1807. The procedure and process were explained to all patients and written consent (local language) was obtained. This prospective, clinical crossover experiment was a randomized splitmouth controlled trial performed between January 2018 to

Table 1. Patient selection and withdrawal criteria

\begin{tabular}{|c|c|}
\hline Inclusion criteria selection & Exclusion criteria selection \\
\hline a) Patient aged between 18 and 45 years & $\begin{array}{l}\text { a) The patient has the systemic disease such as hypertension, cardiovascular problems, } \\
\text { renal and/or liver failure or other serious medical condition(s). }\end{array}$ \\
\hline b) No systemic disease. & b) The patient is pregnant or a lactating mother. \\
\hline c) Non-smoker and non-alcoholic & c) The patient is allergic to local anesthetic agent used. \\
\hline $\begin{array}{l}\text { d) Patient with symmetrically positioned maxillary } \\
\text { impacted third molars on both sides. }\end{array}$ & $\begin{array}{l}\text { d) The patient has facial deformities that may interfere with the local anesthetic injections } \\
\text { for surgery or evaluation. }\end{array}$ \\
\hline e) Patient who granted written consent for the study. & $\begin{array}{l}\text { e) There is swelling and/or infection associated with the maxillary impacted third } \\
\text { molar site. }\end{array}$ \\
\hline $\begin{array}{l}\text { f) The patient can understand and carry out the } \\
\text { instructions given by the investigators. }\end{array}$ & $\begin{array}{l}\text { f) The patient has taken any medication during the } 5 \text { days prior to the surgery that would } \\
\text { alter their perception of pain (analgesic, antidepressants). } \\
\text { g) Inability of patient to follow the instructions or cooperate during the study. }\end{array}$ \\
\hline
\end{tabular}

Withdrawal criteria: The patients can withdraw their participation in the study at any time.

Som Sochenda et al: Buccal infiltration injection without a 4\% articaine palatal injection for maxillary impacted third molar surgery. J Korean Assoc Oral Maxillofac Surg 2020

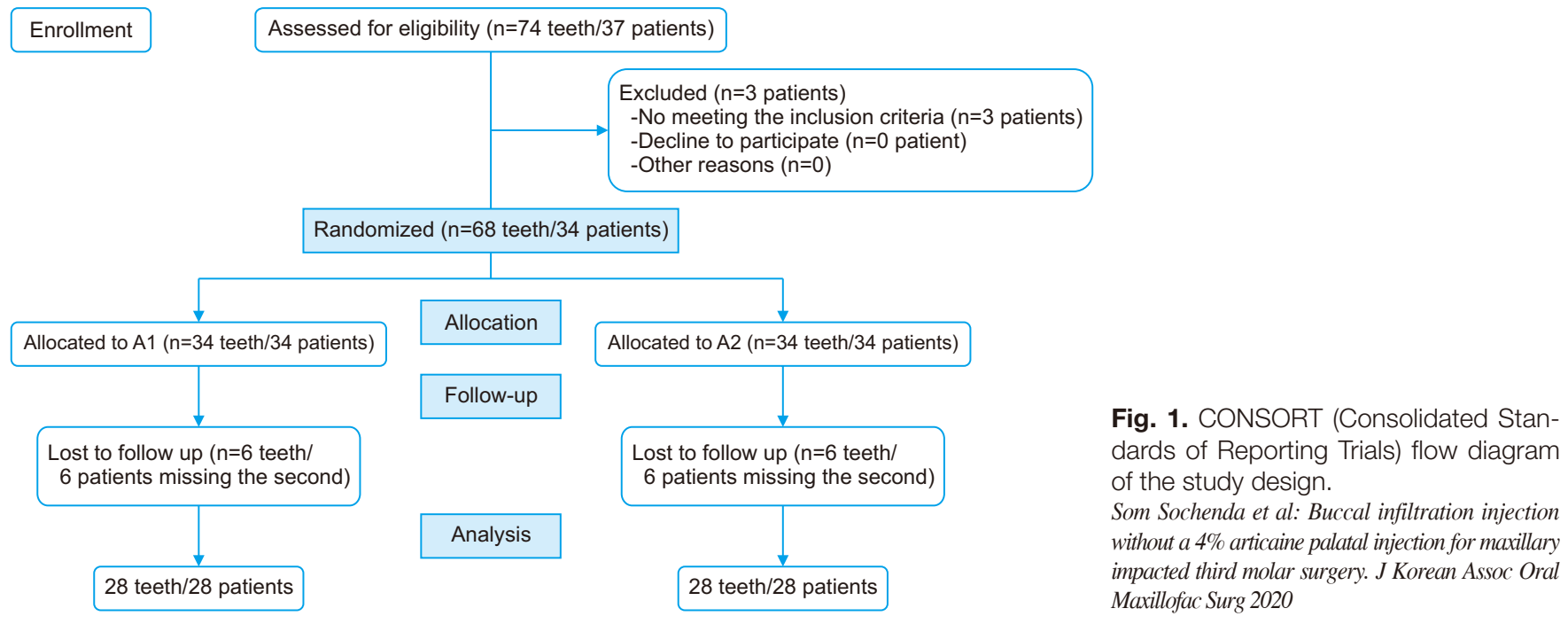


September 2018 in the Department of Oral and Maxillofacial Surgery, Faculty of Dentistry, Mahidol University, Thailand.

The clinical crossover experiment included 28 adult patients who met the eligibility criteria and withdrawal criteria, as shown in Table 1. The sample consisted of 10 males $(35.7 \%)$ and 18 females $(64.3 \%)$, with a mean age of 23 years (range, 18-45 years).

\section{Sample size calculation}

Sample size was calculated using the G*Power 3.1.0 software program, assuming $\alpha$ error was 0.05 , power was $95 \%$ and the estimated effect size was 0.4 with 0.3 to 0.5 as a moderate effect. After our pilot study, we calculated our sample size following the related formula recommendations. The total sample size and additional patients included to allow for withdrawal was at least 27 to 28 patients. The CONSORT (Consolidated Standards of Reporting Trials) flow diagram of this study design is shown in Fig. 1.

Data collection was done at the Oral and Maxillofacial Surgery Clinic, Faculty of Dentistry, Mahidol University, Bangkok, Thailand. All patients were randomly assigned to use the local anesthetic solution by a simple random method (coin tossing).

\section{Maxillary impacted third molar data}

Panoramic radiography was used to evaluate the type and difficulty of impaction. All of the impacted teeth were bilaterally symmetrical. These impactions were evaluated by two expert radiologists and categorized based on the angulation and position, as shown in Table 2 . The difficulty of impacted teeth was divided in 3 groups: very difficult, moderate difficult, and slightly difficult, which were found to be $32.1 \%$,

Table 2. Angulation and position of impact

\begin{tabular}{lr}
\hline Third molar & Value \\
\hline Angle of impact & \\
Distoangular & $13(46.4)$ \\
Vertical & $12(42.9)$ \\
Mesioangular & $3(10.7)$ \\
Total & $28(100)$ \\
Impact position & \\
Position A & $3(10.7)$ \\
Position B & $16(57.1)$ \\
Position C & $9(32.1)$ \\
Total & $28(100)$
\end{tabular}

Values are presented as number (\%).

Som Sochenda et al: Buccal infiltration injection without a $4 \%$ articaine palatal injection for maxillary impacted third molar surgery. J Korean Assoc Oral Maxillofac Surg 2020
$57.1 \%$, and $10.7 \%$ of total cases respectively.

\section{Study methods}

Each patient attended two appointments for two different interventions within 3 weeks to allow for a washout period. The patient received different anesthetic injection techniques at each appointment. A pinprick test was done on the soft tissue at the gingiva of the third molar before local anesthetic administration, as a baseline assessment of pain. Thereafter, in the study group, buccal vestibule infiltration of $4 \%$ articaine with 1:100,000 epinephrine ( 1 cartridge $=1.7 \mathrm{~mL}$ ) was injected without palatal infiltration (Fig. 2) and in the control group, buccal and palatal infiltration of $4 \%$ articaine with 1:100,000 epinephrine was injected for MITMS.

All operations were performed by one expert surgeon for injecting local anesthetic solution, and another surgeon served as the operator. Operative procedures were carried out by the standard technique, using the standard surgical extraction set for MITMS.

\section{Data collection}

The following patient measurements were collected by the operator only:

(1) Hemodynamic parameters (blood pressure and heart rate) were assessed using an Automatic Sphygmomanometer device at the time of the surgical procedure.

(2) The pain VAS score was noted at 10 minutes post-

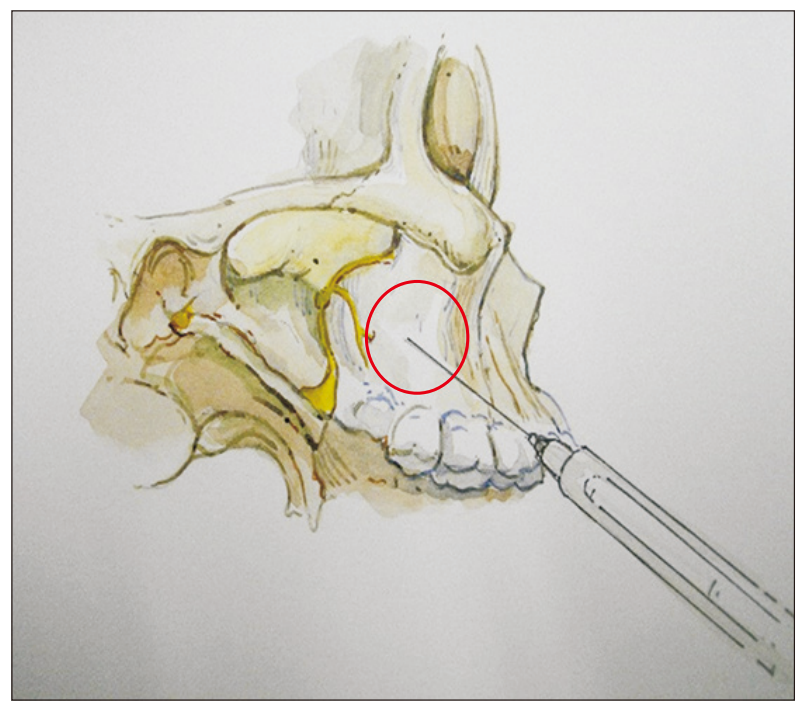

Fig. 2. Buccal vestibule infiltration injection technique. Som Sochenda et al: Buccal infiltration injection without a $4 \%$ articaine palatal injection for maxillary impacted third molar surgery. J Korean Assoc Oral Maxillofac Surg 2020 
injection and immediately postoperation.

(3) The pain numeric rating scale was used to evaluate the intraoperative pain.

(4) Standard postoperative medications were given to every patient after the intervention.

\section{Data analysis}

The data was coded and filled in the Microsoft Excel 2010 (Microsoft, Redmond, WA, USA) and analyzed using the IBM SPSS Statistics (ver. 18.0 for Windows; IBM, Armonk, NY, USA) with the level of significance set at $P<0.05$. Statistical analysis was done using the paired t-test, McNemar's test, and the Pearson correlation test.

\section{Results}

This study found that using 4\% articaine with 1:100,000 epinephrine in a buccal infiltration injection without a palatal injection had a success rate of $78.6 \%$, whereas an $89.3 \%$ success rate was achieved using 4\% articaine with 1:100,000 epinephrine in buccal with palatal infiltration injections. The results for both groups were not statistically significant at a

Table 3. Local anesthesia and surgical time success rates

\begin{tabular}{|c|c|c|c|}
\hline \multirow[b]{2}{*}{ Success rate } & \multicolumn{2}{|c|}{$\begin{array}{l}4 \% \text { articaine } \mathrm{HCl} \text { with } \\
1: 100,000 \text { epinephrine }\end{array}$} & \multirow[b]{2}{*}{$P$-value } \\
\hline & $\begin{array}{l}\text { Buccal } \\
\& \text { palatal } \\
\text { injection }\end{array}$ & $\begin{array}{l}\text { Buccal } \\
\text { injection }\end{array}$ & \\
\hline No. of patients (\%) & $25(89.3)$ & $22(78.6)$ & 0.083 \\
\hline
\end{tabular}

Som Sochenda et al: Buccal infiltration injection without a $4 \%$ articaine palatal injection for maxillary impacted third molar surgery. J Korean Assoc Oral Maxillofac Surg 2020

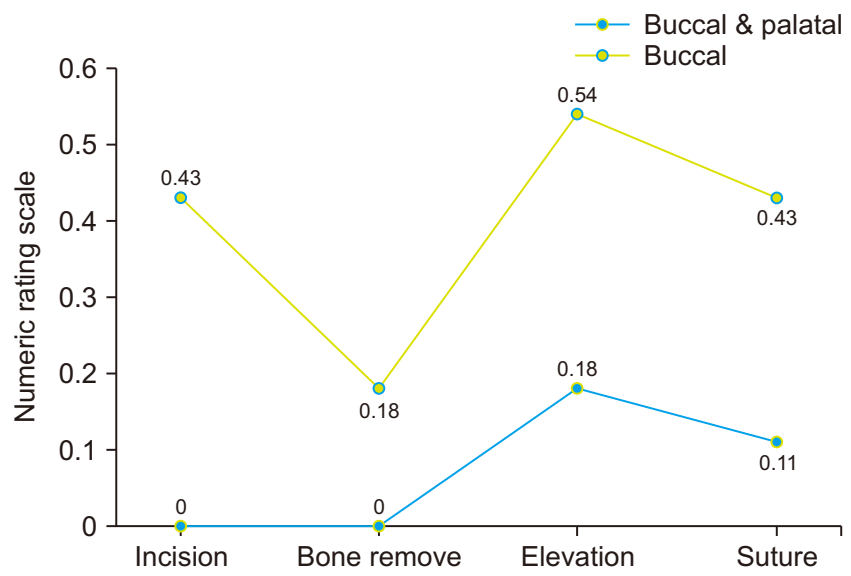

Fig. 3. Intraoperative pain intensity.

Som Sochenda et al: Buccal infiltration injection without a $4 \%$ articaine palatal injection for maxillary impacted third molar surgery. J Korean Assoc Oral Maxillofac Surg 2020
$P$-value of 0.083.(Table 3)

In this study, $21.4 \%$ ( 6 out of 28 cases) and $10.7 \%$ ( 3 out of 28 cases) required additional local anesthetic solution for pain control in the study and control groups, respectively. However, additional anesthetic solution requirements between the two groups were not statistically significant at a $P$-value of 0.083 .

Pain intensity was assessed with a numeric rating scale which showed a gradual increase in pain during the operation until the tooth elevation stage, during which patients experienced the maximum recorded pain, and decreased to nearly baseline at the wound suture stage.(Fig. 3) In addition, the data from the two groups were not statistically significant in all procedure stages at a $P>0.05$.

This study found that based on VAS assessment, administration of $4 \%$ articaine with 1:100,000 epinephrine injection was higher in the buccal and palatal infiltration injection group (30.0) than in the buccal infiltration without palatal injection group (20.0), and this result was statistically significantly different $(P=0.006)$. However, the anesthetic efficacy was not significantly greater in the buccal and palatal infiltration injection group (2.14), compared to the buccal infiltration without palatal injection group (1.79) at a $P$-value of

Table 4. Volunteer visual analogue scale (VAS) during injection and postoperative pain assessment

\begin{tabular}{lcll}
\hline \multicolumn{1}{c}{ VAS } & $\begin{array}{c}\text { Buccal \& } \\
\text { palatal group }\end{array}$ & $\begin{array}{c}\text { Buccal } \\
\text { group }\end{array}$ & $P$-value \\
\hline Injection & 30.0 & 20.0 & $0.006^{*}$ \\
Postoperative & 2.14 & 1.79 & 0.846 \\
\hline
\end{tabular}

$* P<0.05$.

Som Sochenda et al: Buccal infiltration injection without a $4 \%$ articaine palatal injection for maxillary impacted third molar surgery. J Korean Assoc Oral Maxillofac Surg 2020

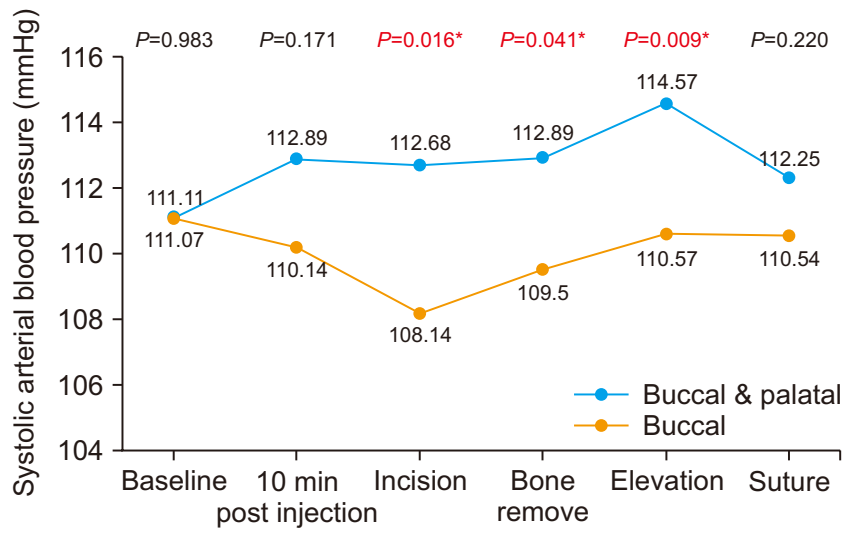

Fig. 4. Systolic arterial blood pressure $(\mathrm{mmHg})$ and local anesthetic administration over time.

Som Sochenda et al: Buccal infiltration injection without a $4 \%$ articaine palatal injection for maxillary impacted third molar surgery. J Korean Assoc Oral Maxillofac Surg 2020 


\subsection{6.(Table 4)}

Fig. 4 shows the systolic blood pressure change during different periods of surgical intervention between the two groups. A statistically significant difference was shown after incision at a $P$-value of 0.016 , bone removal at a $P$-value of 0.041 , and tooth elevation period at a $P$-value of 0.009 .

Consistent with this study, Fig. 5 shows elevation of diastolic blood pressure over different periods of surgical intervention between the two groups and that the data were significantly different at the incision stage, at a $P$-value of 0.036 .

Evaluation of heart rate during different time points of the procedure showed an increase in heart rate in the buccal and palatal infiltration injection group during the 10 minutes postinjection period stage, compared with the study group at a $P$ value of 0.004.(Fig. 6)

\section{Discussion}

This study was performed to assess the effectiveness of $4 \%$ articaine with 1:100,000 epinephrine in buccal infiltration without palatal infiltration injections, compared with buccal and palatal infiltration for bilateral MITMS. This study is a crossover study that was performed in two groups using $4 \%$ articaine with 1:100,000 epinephrine concentration. Patients that were treated with buccal and palatal infiltration injections were considered as the control group (group 1) and the study group (group 2) consisted of cases with buccal infiltration without palatal infiltration injections to remove the maxillary impacted tooth. The results of this study present similar findings to previous studies that used a local anesthetic solution as anesthesia for operations, however, in our study, selected

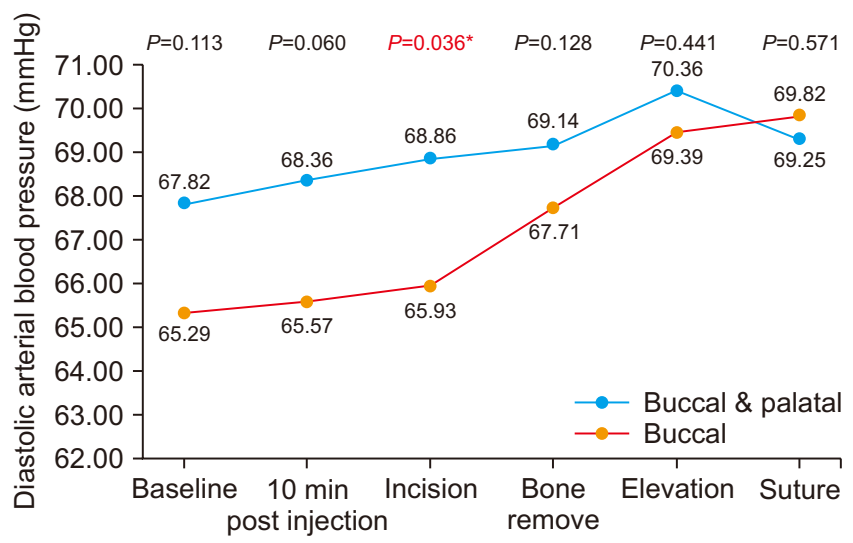

Fig. 5. Diastolic arterial blood pressure $(\mathrm{mmHg})$ and local anesthetic administration over time.

Som Sochenda et al: Buccal infiltration injection without a $4 \%$ articaine palatal injection for maxillary impacted third molar surgery. J Korean Assoc Oral Maxillofac Surg 2020 cases and interventions were different (i.e., difficult bilateral MITMS).

The previous research of Lima-Júnior et al. ${ }^{8}$ explored the efficiency of $4 \%$ articaine with different vasoconstrictors distribution only in buccal infiltration for maxillary impacted third molar removal, and allowed the impacted upper wisdom teeth to be removed without additional palatal injection. Moreover, this study showed that an infiltration injection of 4\% articaine with 1:100,000 epinephrine in the buccal and palatal region gave better diffusion than for cases without palatal injection ${ }^{13}$.

While performing surgery in the maxillary third molar area, precautions with injection techniques and procedures are necessary as this area is prone to the risk of severe bleeding due to its close proximity to the posterior superior alveolar artery and pterygoid venous plexus ${ }^{14}$.

Another study by Bataineh and Al-Sabri ${ }^{9}$ assessed pain control using 4\% articaine with 1:100,000 epinephrine with a buccal infiltration injection only and compared the anesthetic effect and pain control between the anterior and posterior region of the maxilla, and found that $90.6 \%$ of the erupted maxillary teeth extractions did not require a palatal infiltration injection. Therefore, Bataineh and Al-Sabri ${ }^{9}$ established that $4 \%$ articaine with $1: 100,000$ epinephrine is sufficient to anesthetize the palatal area to extract maxillary teeth without requiring another palatal injection in both the anterior and posterior regions.

Although the preemptive, intraoperative and postoperative analgesic techniques have been used in practice for pain con$\operatorname{trol}^{15}$, the use of one injection buccally can minimize pain that is experienced in the palate. A previous study by Uckan et al. ${ }^{10}$ assessed pain intensity during permanent maxillary tooth

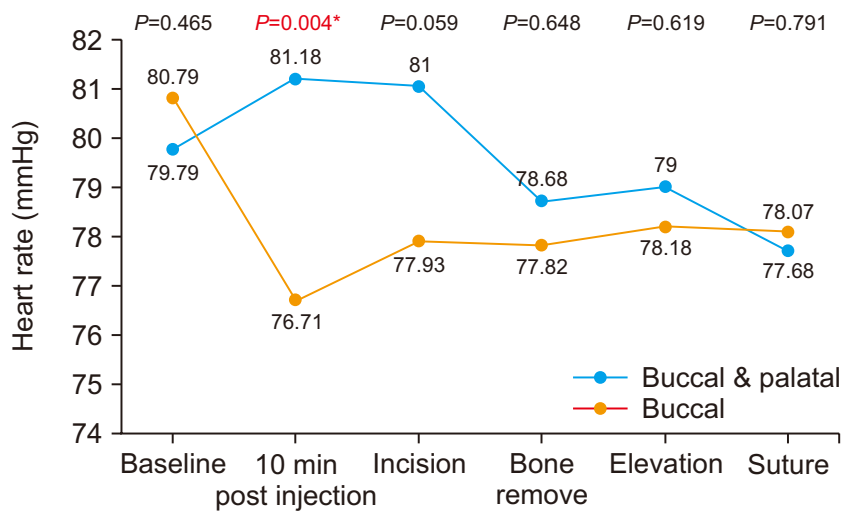

Fig. 6. Heart rate $(\mathrm{mmHg})$ and local anesthetic administration over time.

Som Sochenda et al: Buccal infiltration injection without a $4 \%$ articaine palatal injection for maxillary impacted third molar surgery. J Korean Assoc Oral Maxillofac Surg 2020 
extraction using 4\% articaine with 1:100,000 epinephrine and compared buccal infiltration only and both buccal and palatal injections; the results showed that tooth removal was successful with just the buccal injections or in cases where labial infiltration was given.

A previous, randomized controlled trial by Badcock et al. ${ }^{11}$ compared extraction pain in the maxillary third molar using $2 \%$ lidocaine with 1:80,000 epinephrine in a buccal vestibular infiltration and on one of the palatal sides where an additional $0.2 \mathrm{~mL}$ of lignocaine without a vasoconstrictor was injected, in contrast with the other side which received an equal volume of normal saline. This study found that none of the patients requested additional anesthesia in the palate and that tooth removal was successful and did not require additional palatal administration of lignocaine, in maxillary third molar surgery.

A previous study by Fan et al. ${ }^{12}$ detailed maxillary tooth extraction with and without a palatal injection using 4\% articaine and 1:100,000 epinephrine. The pain assessment by a VAS found no significant difference between the type of injection technique, without a request for a supplementary palatal injection. Therefore, the pain and discomfort experienced when a palatal injection is given can be avoided by using articaine as a local anesthetic agent.

Palatal infiltration injection is associated with the most discomfort and has been identified as the most painful technique out of all injections that are administered in the oral cavity for dental treatment because the palatal tissue is tight and toughly bound to the periosteum and contains an abundance of nerve bundles ${ }^{10}$. The study by Sharma et al. ${ }^{16}$ also supported the hypothesis that removal of upper permanent teeth may not require additional palatal infiltration for anesthesia.

However, the previous study by Somuri et al. ${ }^{17}$ also assessed the use of single buccal infiltration with $4 \%$ articaine/ $\mathrm{HCl}$ and $2 \%$ lidocaine $\mathrm{HCl}$ injection in the buccal and palatal side for maxillary premolar extraction. They concluded that palatal injection may not be essential when $4 \%$ articaine with $1: 100,000$ epinephrine is used for maxillary premolar extraction, considering that buccal infiltration is sufficient and can diffuse more readily into bone and soft tissue, and that palatal tissue anesthesia can also be applied for a more comfortable extraction.

In 2011 Martin et al. ${ }^{18}$ studied the anesthetic efficacy between a single $(1.8 \mathrm{~mL})$ and double dose $(3.6 \mathrm{~mL})$ of $4 \%$ articaine in primary mandibular buccal infiltration of the first molar using an electric pulp tester in 3 minutes cycles for 90 minutes after injection. The result showed a greater success rate $(70 \%$ vs $50 \%)$ for anesthesia with the use of a $3.6 \mathrm{~mL}$ volume of articaine.

In this study, each group underwent an alternative technique that used 4\% articaine and 1:100,000 epinephrine in buccal infiltration injections without palatal infiltration injections, in comparison with buccal and palatal infiltration injections. During the first period after injection without additional anesthesia, an increase in systolic blood pressure was noted in the buccal and palatal infiltration group, and the result was statistically significant compared with the study group.

This outcome was similar to the previous study by Sharma et al. ${ }^{16}$ in which the systolic blood pressure slightly increased within 5 minutes after the injection of each anesthetic that was administered, and then, within an hour of the injection, it returned to the baseline value. The buccal and palatal infiltration group had higher levels of hemodynamic change during operation, especially during the tooth elevation period. Many previous studies have concluded that there are various factors that are responsible for changes in hemodynamic levels during dental treatment, such as anxiety ${ }^{19}$, endogenous and exogenous epinephrine plasma levels ${ }^{20,21}$, types of operation, and volume of local anesthetic used $\mathrm{d}^{13,22,23}$.

\section{Conclusion}

This study determined that there was a similar clinical efficacy when 4\% articaine with 1:100,000 epinephrine was used for the buccal infiltration injection without a palatal injection compared to both buccal infiltrations with palatal injections for surgical extraction of the maxillary impacted third molar. Our results indicate that $4 \%$ articaine used with the buccal infiltration injection technique can be an alternative to the buccal with palatal infiltration approach which could be preferable for patients. Overall, this approach can be used to optimize patient care and no adverse effects would be expected for healthy adult patients.

\section{ORCID}

Som Sochenda, https://orcid.org/0000-0002-0397-7728

Chakorn Vorakulpipat, https://orcid.org/0000-0001-66278732

Kumar K C, https://orcid.org/0000-0001-9620-7388

Chavengkiat Saengsirinavin, https://orcid.org/0000-00031344-5036

Manus Rojvanakarn, https://orcid.org/0000-0002-99868998 
Natthamet Wongsirichat, https://orcid.org/0000-0003-30052680

\section{Authors' Contributions}

S.S. participated in methodology, validation, investigation, resources, data curation, and writing - original draft preparation. C.V. participated in supervision, project administration, and conceptualization. K.K.C. participated in writingreview and editing and formal analysis. C.S. participated in supervision, conceptualization, and methodology. M.R. participated in supervision. N.W. participated in project administration and conceptualization.

\section{Acknowledgements}

The authors would like to thank the staff and dental assistants, including colleagues and co-workers in the Department of Oral and Maxillofacial Surgery, Faculty of Dentistry, Mahidol University.

\section{Ethics Approval and Consent to Participate}

This research was approved by the Committee in the Ethics of Research in Human Beings of Dentistry and Pharmacy of the Mahidol University Institutional Review Board with protocol No. COA MU-DT/PY-IRB 2018/039.1807.

\section{Conflict of Interest}

No potential conflict of interest relevant to this article was reported.

\section{References}

1. McCoy JM. Complications of retention: pathology associated with retained third molars. Atlas Oral Maxillofac Surg Clin North Am 2012;20:177-95. https://doi.org/10.1016/j.cxom.2012.06.002

2. Rakprasitkul S. Pathologic changes in the pericoronal tissues of unerupted third molars. Quintessence Int 2001;32:633-8.

3. Colombini BL, Modena KC, Calvo AM, Sakai VT, Giglio FP, Dionísio TJ, et al. Articaine and mepivacaine efficacy in postoperative analgesia for lower third molar removal: a double-blind, randomized, crossover study. Oral Surg Oral Med Oral Pathol Oral Radiol Endod 2006;102:169-74. https://doi.org/10.1016/ j.tripleo.2005.09.003

4. McArdle BF. Painless palatal anesthesia. J Am Dent Assoc 1997;128:647. https://doi.org/10.14219/jada.archive.1997.0265

5. Gregorio LV, Giglio FP, Sakai VT, Modena KC, Colombini BL, Calvo AM, et al. A comparison of the clinical anesthetic efficacy of $4 \%$ articaine and $0.5 \%$ bupivacaine (both with 1:200,000 epinephrine) for lower third molar removal. Oral Surg Oral Med Oral
Pathol Oral Radiol Endod 2008;106:19-28. https://doi.org/10.1016/ j.tripleo.2007.11.024

6. Malamed SF. Handbook of local anesthesia. 6th ed. St. Louis: Mosby; 2012:79.

7. Isik K, Kalayci A, Durmus E. Comparison of depth of anesthesia in different parts of maxilla when only buccal anesthesia was done for maxillary teeth extraction. Int J Dent 2011;2011:575874. https:// doi.org/10.1155/2011/575874

8. Lima-Júnior JL, Dias-Ribeiro E, de Araújo TN, Ferreira-Rocha J, Honfi-Júnior ES, Sarmento CF, et al. Evaluation of the buccal vestibule-palatal diffusion of $4 \%$ articaine hydrochloride in impacted maxillary third molar extractions. Med Oral Patol Oral Cir Bucal 2009;14:E129-32.

9. Bataineh $\mathrm{AB}, \mathrm{Al}-\mathrm{Sabri} \mathrm{GA}$. Extraction of maxillary teeth using articaine without a palatal injection: a comparison between the anterior and posterior regions of the maxilla. J Oral Maxillofac Surg 2017;75:87-91. https://doi.org/10.1016/j.joms.2016.06.192

10. Uckan S, Dayangac E, Araz K. Is permanent maxillary tooth removal without palatal injection possible? Oral Surg Oral Med Oral Pathol Oral Radiol Endod 2006;102:733-5. https://doi.org/10.1016/ j.tripleo.2005.12.005

11. Badcock ME, Gordon I, McCullough MJ. A blinded randomized controlled trial comparing lignocaine and placebo administration to the palate for removal of maxillary third molars. Int $\mathrm{J}$ Oral Maxillofac Surg 2007;36:1177-82. https://doi.org/10.1016/ j.ijom.2007.06.001

12. Fan S, Chen WL, Yang ZH, Huang ZQ. Comparison of the efficiencies of permanent maxillary tooth removal performed with single buccal infiltration versus routine buccal and palatal injection. Oral Surg Oral Med Oral Pathol Oral Radiol Endod 2009;107:35963. https://doi.org/10.1016/j.tripleo.2008.08.025

13. Lima JL Jr, Dias-Ribeiro E, Ferreira-Rocha J, Soares R, Costa FW, Fan $\mathrm{S}$, et al. Comparison of buccal infiltration of $4 \%$ articaine with $1: 100,000$ and $1: 200,000$ epinephrine for extraction of maxillary third molars with pericoronitis: a pilot study. Anesth Prog 2013;60:42-5. https://doi.org/10.2344/0003-3006-60.2.42

14. Park WH, Choi SY, Kim CS. Study on the position of the posterior superior alveolar artery in relation to the performance of the maxillary sinus bone graft procedure in a Korean population. J Korean Assoc Oral Maxillofac Surg 2012;38:71-7. https://doi.org/10.5125/ jkaoms.2012.38.2.71

15. Lima TC, Bagordakis E, Falci SGM, Dos Santos CRR, Pinheiro MLP. Pre-emptive effect of dexamethasone and diclofenac sodium associated with codeine on pain, swelling, and trismus after third molar surgery: a split-mouth, randomized, triple-blind, controlled clinical trial. J Oral Maxillofac Surg 2018;76:60-6. https://doi. org/10.1016/j.joms.2017.06.012

16. Sharma K, Sharma A, Aseri M, Batta A, Singh V, Pilania D, et al. Maxillary posterior teeth removal without palatal injection -truth or myth: a dilemma for oral surgeons. J Clin Diagn Res 2014;8:ZC014. https://doi.org/10.7860/JCDR/2014/10378.5092

17. Somuri AV, Rai AB, Pillai M. Extraction of permanent maxillary teeth by only buccal infiltration of articaine. J Maxillofac Oral Surg 2013;12:130-2. https://doi.org/10.1007/s12663-012-0396-0

18. Martin M, Nusstein J, Drum M, Reader A, Beck M. Anesthetic efficacy of $1.8 \mathrm{~mL}$ versus $3.6 \mathrm{~mL}$ of $4 \%$ articaine with $1: 100,000$ epinephrine as a primary buccal infiltration of the mandibular first molar. J Endod 2011;37:588-92. https://doi.org/10.1016/ j.joen.2011.01.001

19. Brand HS, Abraham-Inpijn L. Cardiovascular responses induced by dental treatment. Eur J Oral Sci 1996;104:245-52. https://doi. org/10.1111/j.1600-0722.1996.tb00074.x

20. Sapira JD, Bron K. Human epinephrine secretion. Direct measurement of the secretion of epinephrine from the human adrenal medulla. J Clin Endocrinol Metab 1971;33:436-47. https://doi. org/10.1210/jcem-33-3-436

21. Lipp M, Dick W, Daubländer M, Fuder H, Stanton-Hicks M. Exog- 
enous and endogenous plasma levels of epinephrine during dental treatment under local anesthesia. Reg Anesth 1993;18:6-12.

22. Troullos ES, Goldstein DS, Hargreaves KM, Dionne RA. Plasma epinephrine levels and cardiovascular response to high administered doses of epinephrine contained in local anesthesia. Anesth Prog 1987;34:10-3.

23. de Morais HH, de Santana Santos T, Araújo FA, Vajgel A, de Holanda Vasconcellos RJ. Hemodynamic changes comparing lidocaine $\mathrm{HCl}$ with epinephrine and articaine $\mathrm{HCl}$ with epinephrine. J Craniofac Surg 2012;23:1703-8. https://doi.org/10.1097/ SCS.0b013e31826bec 3b
How to cite this article: Sochenda S, Vorakulpipat C, K C K, Saengsirinavin C, Rojvanakarn M, Wongsirichat N. Buccal infiltration injection without a $4 \%$ articaine palatal injection for maxillary impacted third molar surgery. J Korean Assoc Oral Maxillofac Surg 2020;46:250-257. https://doi.org/10.5125/jkaoms.2020.46.4.250 